\title{
Surgical Treatment of Rotator Cuff Tears After 65 Years of Age: A Systematic Review
}

\author{
Tratamento Cirúrgico de Roturas da Coifa dos Rotadores \\ em Doentes com Mais de 65 anos: Revisão Sistemática
}

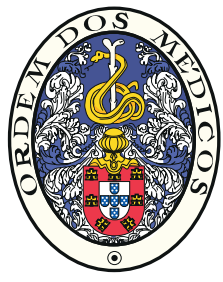

\author{
Bruno Mota SILVA $\rrbracket^{1,2}$, António CARTUCHO², Marco SARMENTO², Nuno MOURA ${ }^{2}$ \\ Acta Med Port 2017 Apr;30(4):320-329 • https://doi.org/10.20344/amp.8307
}

\begin{abstract}
Introduction: The objective of this study was to analyze current evidence regarding surgical management of rotator cuff tears in patients of 65 years of age and above. Our hypothesis was that surgical repair of rotator cuff tears, in patients older than 65 years, conveys good outcome scores. We have not found a similar systematic review in current literature.

Material and Methods: Medline ${ }^{\circledR}$, PubMed, Scopus, and the Cochrane Register of Controlled Trials were searched from January 1999 unto December 2015 for studies, regardless of language, including the words 'rotator cuff' and ' 65 years' or ' 70 years'. Inclusion criteria were studies (level I to IV) that reported clinical outcomes in patients older than 65 years, having undertaken surgical repair of a symptomatic rotator cuff tears. Arthroscopic, mini open and open techniques were included. Exclusion criteria were: studies with patients younger than 65 years, studies that did not use validated outcome evaluation scores as primary assessment tools and those with follow up under one year. This work followed the Preferred Reporting Items for Systematic Reviews and Meta-Analyses - PRISMA guidelines. Data abstracted included patient demographics, tear pattern, surgical procedures, clinical and repair results. Outcome scores were converted to percentages, allowing comparison of data between studies.

Results: After deep analysis, 14 studies met the inclusion criteria: 11 level IV studies, 1 level III study and 2 level II studies. Seven studies found statistically significant outcome improvements between pre and postoperative evaluations. All studies reported good or excellent surgical outcomes.

Discussion: Better results would probably be achieved if all studies had rigorous and homogeneous patient selection criteria, but the fact is, that even though this was not the case, the clinical scores remained favorable, and with statistically significant outcome improvement in all studies with prospectively collected data.
\end{abstract}

Conclusion: Based on current literature, rotator cuff repair in patients older than 65 years imparts favorable improvement in clinical outcome scores and overall patient satisfaction.

Keywords: Aged; Arthroscopy; Rotator Cuff Injuries/surgery; Systematic Review

\section{RESUMO}

Introdução: O objetivo deste estudo, é o de analisar a evidência atual no que respeita ao tratamento cirúrgico de roturas da coifa dos rotadores, em doentes com mais de 65 anos de idade. A hipótese proposta foi que o tratamento cirúrgico de roturas da coifa dos rotadores, em doentes com 65 anos ou mais, acarreta bons resultados funcionais. Não existe, na literatura atual, uma revisão sistemática com os mesmos parâmetros que esta.

Material e Métodos: Recorremos à Medline ${ }^{\circledR}$, PubMed, Scopus, e Cochrane Register of Controlled Trials, na procura de estudos entre janeiro de 1999 e dezembro de 2015, independentemente da língua, que incluíssem as palavras: 'rotator cuff' e '65 years' ou '70 years'. Como critérios de inclusão estipulámos, estudos (nível I a IV) que reportassem os resultados funcionais de doentes com 65 anos ou mais, submetidos à reparação cirúrgica de uma rotura da coifa dos rotadores sintomática. Foram incluídas técnicas artroscópicas, mini-invasivas e abertas. Os critérios de exclusão estipulados foram, estudos que incluíssem doentes com menos de 65 anos, estudos que não recorressem a escalas de avaliação funcional validadas, como ferramenta de aferição primária, e aqueles com tempo de seguimento inferior a um ano. Este trabalho seguiu as orientações da Preferred Reporting Items for Systematic Reviews and Meta-Analyses - PRISMA. A informação colhida incluiu dados demográficos, padrões de rotura, procedimentos cirúrgicos realizados e resultados, clínicos e das reparações efectuadas. Os resultados funcionais foram convertidos em percentagens, permitindo a comparação de dados entre os estudos.

Resultados: Quatorze estudos cumpriram os critérios de inclusão: 11 estudos nível IV, um estudo nível III e dois estudos nível II. Sete estudos reportaram melhorias com significado estatístico entra as avaliações funcionais pré e pós operatórias. Todos os estudos reportaram resultados funcionais bons ou excelentes.

Discussão: É provável que seriam obtidos resultados mais consistentes, se todos os estudos incluídos tivessem critérios de selecção mais homogéneos e rigorosos. Apesar de tal não se ter verificado, os resultados clínicos foram, todavia, favoráveis. Isto traduziu-se numa melhoria dos resultados funcionais, com significado estatístico, em todos os estudos prospectivos incluídos.

Conclusão: Com base na literatura atual, a reparação de roturas da coifa dos rotadores em doentes com 65 anos ou mais, está associada à melhoria dos resultados funcionais e a um bom grau de satisfação com o procedimento.

Palavras-chave: Artroscopia; Idoso; Revisão Sistemática; Rotura da Coifa dos Rotadores

\footnotetext{
1. Orthopaedic Department. Hospital de Nossa Senhora do Rosário. Barreiro. Portugal.

2. Shoulder Unit, Orthopaedic Surgery. Hospital CUF Descobertas. Lisboa. Portugal.

$\bowtie$ Autor correspondente: Bruno Mota Silva. b.motanogueira@gmail.com

Recebido: 14 de outubro de 2016 - Aceite: 16 de fevereiro de 2017 | Copyright @ Ordem dos Médicos 2017
} 


\section{INTRODUCTION}

\section{Background}

Rotator cuff tears (RCT) are a frequent disorder in elder patients, ${ }^{1}$ and can be of either degenerative or traumatic conditioning. Degenerative RCT have a closely age-related prevalence between $15 \%$ and $51 \%{ }^{2-6}$ Incidence of rotator cuff tears also increases with advancing age, amounting to $80 \%$ in patients older than 80 years. ${ }^{7-9}$ Only one third of these lesions are associated with pain. ${ }^{3}$ The onset of pain may be caused by progression of a lesion, either as expansion in size of a full-thickness tear or as a conversion of a partial lesion into a full-thickness one. ${ }^{10}$ Alternative factors have been associated with progressive pain, including age, fatty infiltration, alteration of gleno-humeral kinematics and biceps tendon disorders. ${ }^{11-15}$ Recently, in a study with a mean population age of 70 years, $50 \%$ of asymptomatic tears become symptomatic at a mean of 2.8 years. ${ }^{5}$ Traumatic rotator cuff tears ordinarily occur in individuals nearly 10 years younger than the population affected by degenerative lesions,$^{16}$ having a more favorable prognosis, with higher rates of successful healing following repair. ${ }^{17}$ Furthermore, with the enlarged life expectancy and enhanced medical treatment, many elders remain active longer, with high functional demands. ${ }^{18,19}$ Symptomatic rotator cuff tears that are unresponsive to conservative measures remain in controversy regarding definitive treatment in older patients, ${ }^{18}$ particularly in those past 65 years of age. These patients, with persistent pain and shoulder disability leading to loss of functional independence, may have surgical treatment as the most viable option. Despite the lack of a unanimous agreement regarding the success of rotator cuff repair (RCR) in such cases, it is an acknowledged fact that rotator cuff disease alone is a primary determinant of health status and consequently, surgery for rotator cuff disease reliably and significantly improves this parameter. ${ }^{20,21}$

\section{Objective and hypothesis}

The objective of this systematic review is to analyze current evidence regarding the treatment of RCTs in patients aged 65 years or older. We tested the hypothesis that there is current evidence, supporting the efficacy of surgical repair of RCT lesions, in the latter age group.

\section{MATERIAL AND METHODS}

\section{Treatment and study designs}

To verify our hypothesis, MEDLINE ${ }^{\circledR}$, PubMed, SCOPUS, and the Cochrane Register of Controlled Trials were searched from January 1999 unto December 2015. Studies Level I to IV that reported clinical outcomes in patients older than 65 years old, who had undergone surgical repair of a symptomatic (traumatic or degenerative) rotator cuff tear, were included, regardless of language. Valid surgical treatments included: tendon repair, through arthroscopic, mini open or open techniques (using transosseous tunnels, bone troughs or anchors).

Eleven retrospective reviews (one of them, an abstract for which the authors were contacted), one case-control study and two prospective randomized comparative multicenter studies were analyzed.

This systematic review followed the Preferred Reporting Items for Systematic Reviews and Meta-Analyses (PRISMA) guidelines. ${ }^{22}$ Data attained from the studies included patient demographics, tear pattern, surgical procedures and clinical outcome as well as repair outcome.

\section{Study populations and clinical scores}

Selected studies strictly included patients above 65 years of age. Clinical outcome scores applied included the Constant Shoulder Score (CSS), ${ }^{23}$ Simple Shoulder Test (SST), ${ }^{24}$ Oxford Shoulder Score (OSS), ${ }^{25}$ American Shoulder and Elbow Surgeons Score (ASES), ${ }^{16}$ Disabilities of the Arm, Shoulder and Hand Score (DASH), ${ }^{26}$ Short Form12 Health Survey Physical Component Summary (SF 12 PCS), ${ }^{27}$ Single Assessment Numeric Evaluation (SANE), ${ }^{28}$ and UCLA (University of California at Los Angeles Shoulder Rating Scale)..29 Other subjective measures included: the SSA (Senior Shoulder Activity Score) ${ }^{30}$ and VAS (Visual Analogue Scale) ${ }^{31}$

Validated outcome scores were converted to percentages providing analytical comparison between the reviewed studies.

\section{Search strategy}

Subsequently to establishing a protocol, the search of published studies, regardless of language, that reported surgical treatment outcomes of complete rotator cuff tears after the age of 65 , was implemented. Medline was searched through PubMed for articles published from January 1999 unto December 2015. Analyzing the medical subject headings $(\mathrm{MeSH})$ terms for preliminary searching, it was concluded that premises which were not $\mathrm{MeSH}$ headings would retrieve more search results. Thereby, we employed words that defined the overall goal of the search and PubMed searched them on the title and abstract, inferring the respective $\mathrm{MeSH}$ and identifying all the mapped publications. The imperative terms in our strategy were: '65 years', '70 years' and 'rotator cuff'. All relevant papers had either 65 years or 70 years old as an age limit. Therefore, our query was: ((70 years) OR 65 years) AND rotator cuff. 'Rotator cuff' was inferred as a MeSH term and searched in all fields; the terms 'rotator', as well as 'cuff', were also searched independently. This search method was applied upon conducting our preliminary search and concluding that it would help exclude studies involving patients younger than 65 years. The decision of limiting the systematic review to publications including uniquely patients over the age of 65 , allowed a reduction of study cases including smaller patient populations meeting our inclusion criteria, diminishing heterogeneity, thus reducing the risk of bias. An identical search strategy, with necessary adaptations, was repeated for the Scopus and the Cochrane Register of Controlled Trials.

Inclusion criteria were, as mentioned previously: patients 
older than 65 years of age with a RCT (diagnose confirmed by magnetic resonance imaging, ultrasound, surgery or arthrography). Studies where associated procedures took place were included. Exclusion criteria included articles reporting outcomes of patients younger than 65 years, isolated tears of the subscapularis tendon and grafting or tendon transfer procedures.

An effort was made to include all studies - one in particular was unavailable as a full paper and was included in abstract format. The authors were consequently contacted by Researchgate ${ }^{\circledR}$ and letter, requesting additional information on the published work. All articles included for revision of appropriateness for assessing the hypothesis were blinded, the level of evidence of each selected study was assessed by the evaluators. As articles were selected, the respective references were also reviewed and cross-referenced. Hand search was used to further identify articles within our criteria throughout the bibliographic references.

Statistical analysis was performed using SPSS 23.0 software (SPSS Inc, Chicago, IL). All data was extracted by one reviewer and independently verified by the second.

\section{RESULTS}

\section{Study types}

As depicted in Fig. 1, 365 articles were initially selected for evaluation based on the described search strategy protocol. Eleven level IV studies, one level III study and two level II studies were ultimately included in this systematic review. One of the level IV studies was included in the abstract format. The level III study was a case control study, comparing two main groups: Group 1, surgical repair (healed and non-healed) and Group 2, no repair (tear and no-tear). Both level II studies were prospective, randomized multicenter studies; one of them compared a group of patients submitted to acromioplasty alone versus a RCT repair plus acromioplasty. The results were compared according to level of evidence, and treatment type.

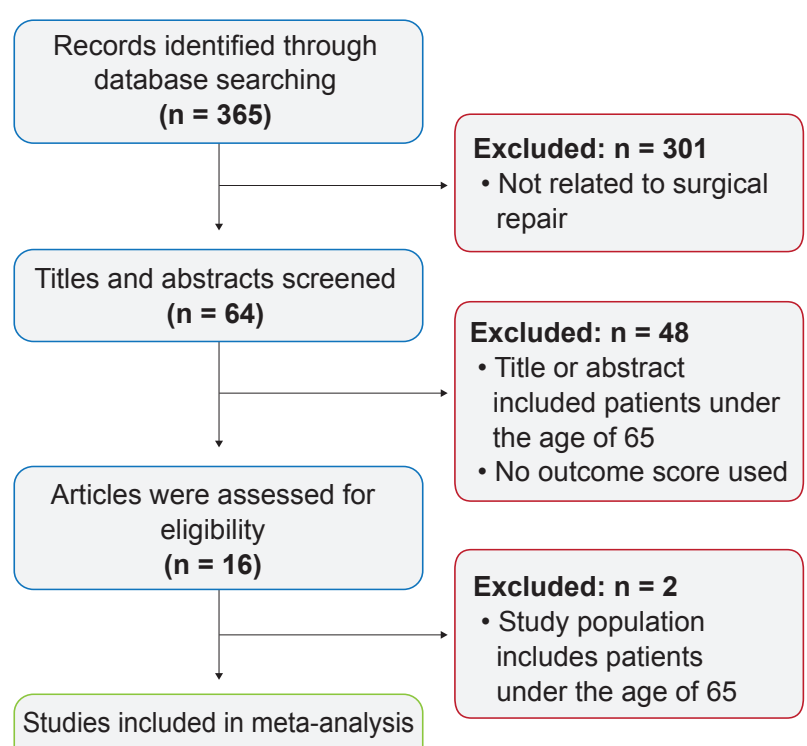

Figure 1 - Flow diagram of study selection

\section{Study demographics}

Seven studies reported outcomes in patients aged 70 years or older, the other seven studies measured outcomes in patients 65 years and above. The mean age of the patients included in all studies was 73.21 (SD \pm 2.41 ). Even though the minimum age criterion was different between studies, the mean age between studies was homogeneous (Tables 1 and 2).

A total number of 973 patients and 997 shoulders were abstracted from the analyzed studies.

Two studies included a mini-open technique, three studies included an all-open technique, one study included patients who had undergone either open or arthroscopic techniques and eight studies evaluated patients after an

Table 1 - Study demographics

\begin{tabular}{|c|c|c|c|c|c|}
\hline First author, Year & Pop. (n) & Proc. (n) & Male (\%) & DS (\%) & AT $(\%)$ \\
\hline Bhatia, 2015 & 44 & 49 & 75.0 & NA & 24.0 \\
\hline Charousset, 2010 & 81 & 81 & 33.3 & 88.9 & 86.9 \\
\hline De Carvalho, 2012 & 80 & 88 & 72.7 & NA & NA \\
\hline Djahangiri, 2013 & 41 & 44 & 59.1 & 77.3 & 43.1 \\
\hline Fehringer, 2010 & 39 & 42 & 64.3 & NA & NA \\
\hline Flurin, 2013 & 135 & 135 & 37.0 & NA & 29.0 \\
\hline Flurin, 2013 & 70 & 70 & 37.0 & NA & NA \\
\hline Lam, 2004 & 69 & 69 & 59.4 & 78 & 61.0 \\
\hline Miyazaki, 2014 & 163 & 163 & 38.7 & 66.3 & 38.0 \\
\hline Robinson, 2013 & 68 & 69 & 49.3 & NA & NA \\
\hline De Castro Veado, 2015 & 28 & 28 & 21.4 & 64.2 & NA \\
\hline Verma, 2010 & 39 & 39 & 46.2 & 53.8 & NA \\
\hline Worland, 1999 & 69 & 69 & 39.9 & NA & NA \\
\hline Yel, 2001 & 47 & 51 & NA & NA & NA \\
\hline
\end{tabular}

AT: Associated trauma; DS: Dominant shoulder; NA: Not available; Pop: Population; Proc: Procedures 
all-arthroscopic technique. All studies had clear objectives and four also fulfilled the hypothesis requirement (one level IV, one level III, both level II studies).

Male patients were reported in an inferior percentage relatively to the female population in eight studies. ${ }^{19,32-38}$ Overall average incidence of male patients was $48.72 \%$ (range $21.4 \%$ - 64.3\%). Hand dominance was reported in 6 studies, ${ }^{19,32,35,37,39,40}$ in which, the dominant shoulder was affected in $71.41 \%$ [53.8\% - 88.9\%]. History of a previous traumatic event was described in 6 studies, ${ }^{32,34,35,39-41}$ the overall percentage of patients with a traumatic history was $50.6 \%$ [24\% - 86.9\%]. In Robinson's paper, ${ }^{36}$ shoulders in males were estimated to have a one year postoperative CSS that was a mean 15.5 points (95\% Cl 5.25 to 25.7 ) greater than in their female counterparts.

\section{Study objectives}

Evidence level IV. We have found homogeneity in the level IV studies' objectives. Carvalho et $a^{42}$ set the objective to retrospectively evaluate outcome results in patients over the age of 70 years, through a mini-open approach, without a control group. The study by Djahangiri et $a^{\beta 9}$ set to review the results of RCR in patients older than 65 years through an open and arthroscopic technique and to identify factors predicting outcome. Robinson et $a^{\beta 6}$ reported the clinical and sonographic outcomes of arthroscopic rotator cuff repair in patients over 70 years of age and aimed to determine factors associated with re-tear. Charousset et $a^{\beta 2}$ set the objective to assess tendon healing and clinical results of RCTs repaired arthroscopically in patients aged 65 years or older. They hypothesized that patients aged 65 years and above could have tendon healing, and consequently, significant functional improvement. In the study by Lam et $a l,{ }^{40}$ the purpose was to evaluate functional outcome and identify possible preoperative prognostic factors in patients aged 65 years or more, undergoing repair for a massive (> 5 $\mathrm{cm}$ ) full-thickness rotator cuff tear. Miyazaki et $a^{\beta 5}$ evaluated the results of arthroscopic surgical treatment of rotator cuff lesions in patients aged 65 years and above. Bhatia et a/ ${ }^{41}$ retrospectively reviewed prospectively collected data, with the objective to evaluate clinical outcome in recreational athletes 70 years of age or older (this study included $8 \%$ patients submitted to revision surgery). De Castro Veado et $a^{\beta 7}$ retrospectively evaluated the results from patients who underwent arthroscopic treatment of rotator cuff injuries, among those aged 65 years, observing integrity, function and strength. Verma et a/ ${ }^{19}$ evaluated outcomes of arthroscopic rotator cuff repair in patients aged 70 years or older with a thorough demographic characterization and ROM measurement. In the study by Worland et al, ${ }^{38}$ the objective was to evaluate the results found in patients older than 70 years who had undergone open surgical repair for massive ruptures of the rotator cuff tendons and to correlate the functional outcome with the quality of the repairs. Yel et $a^{43}$ evaluated clinical results of open rotator cuff repair and subacromial decompression in patients aged 65 years or older.
Evidence level III. In the level III study included in this systematic review, Fehringer et $a l^{44}$ set to question whether in patients 65 years of age and older, shoulders with RCR that remained intact would have SST and CSS scores similar to those of untreated individuals with intact rotator cuffs.

Evidence level II. The level II studies carried by Flurin et $a^{\beta 3,34}$ were multicenter prospective studies conducted in 11 surgical centers and presented in the Société Française d'Arthroscopie (French Arthroscopic Society, SFA) symposium in 2012. Both studies had similar population groups, but set different objectives. The first study ${ }^{33}$ proposed to answer the questions of whether repair of supraspinatus lesions in patients older than 70 years of age is reliable in terms of both clinical results and healing, and whether tendon healing is significantly correlated with the CSS, ASES and SST scores as well as with age, tendon retraction and fatty infiltration. The second study ${ }^{34}$ hypothesized that arthroscopic repair would be superior to decompression in patients with 70 years of age and above, comparing clinical results with each technique as well as analyzing the effects of age, tendon retraction and fatty infiltration on the outcome (paraclinical data in this study was extremely thorough). In the first of these two studies, the population was subdivided in two groups (70 - 74 years and $>75$ years) and the repair outcome was actually superior in the older group.

\section{Inclusion and exclusion criteria}

We found heterogeneity in the inclusion and exclusion criteria between studies, after setting apart the age mark and the surgical technique used. Overall, surgery was indicated in symptomatic patients in whom physiotherapy and medication had failed to reduce pain. The paper published by Bhatia et $\mathrm{al}^{41}$ only included in their study recreational athletes (in a pre-set activity level scale) over the age of 70 years. Some studies included all tear sizes according to the Cofield classification. ${ }^{19,36,38,40,42}$ Lam et a ${ }^{40}$ intra-operatively encountered $>5 \mathrm{~cm}$ full thickness RCT in all patients (postoperative CSS $=63 \%$ ). Some studies excluded massive tears $(>5 \mathrm{~cm}){ }^{33,34,37}$ Multiple tendon lesions were included in all studies under specific limitations..$^{32,39,41,44}$ Verma et a/19 excluded RCT with subscapularis involvement (100\% had supraspinatus and $38.5 \%$ had infraspinatus involvement). Some studies set criteria for tendon reparability including acromio-humeral distance, ${ }^{33,39}$ tendon retraction according to Patte $(<3)^{34}$ and fatty infiltration according to Goutallier $\left.(G<3)^{32,39,41}(G<4)\right)^{33,34}$ Non-reducible tears without tension or requiring intraoperative arthrolysis were excluded in both level II studies. Concomitant procedures were performed in all evaluated studies, there were, however, differences in the procedures, particularly, intra-articular actions (Table 2). In the study by Fehringer et $\mathrm{al}^{44}$ no acromioplasties were performed (mini-open technique, mean CSS $=85 \%$ in patients with healed repairs).

The presence of a partial thickness tear was transversal as exclusion criteria, ${ }^{19,32-34}$ although one study included 
$8 \%$ of partial tears. Previous surgery was also a frequent exclusion factor, ${ }^{32,37,41}$ as well as fractures. Glenohumeral $(\mathrm{GH})$ osteoarthritis (OA) according to Hamada was set as an exclusion criterion for most studies..$^{32-34,37,40}$ Cuff tear arthropathy in a preoperative $\mathrm{x}$-ray was an exclusion criterion in other studies. ${ }^{40}$ The paper by Miyazaki et $a^{\beta 5}$ featured broader inclusion criteria, thus, patients with instability, adhesive capsulitis and arthrosis were included (Table 2), whereas Veado et $a^{\beta 7}$ excluded SLAP and Bankart lesions. Instability was an exclusion criterion in both level II studies. In the study by Bhatia et $a^{41}$ patients with $\mathrm{GH}$ OA grade 3 or 4 (12 cases) were included.

\section{Outcome scores}

Three of the level IV studies didn't have a preoperative baseline clinical score of the patient population. All studies recurred to validated clinical outcome scores, which were relatively heterogeneous: 10 of the studies used the CSS, three used the UCLA, five used ASES, seven used the SST, one used Q-DASH, SF12-PCS and SANE, one used the OSS and another used VAS. Paraclinical evaluations were used in seven studies (Table 2).

\section{Pain and subjective satisfaction scores}

De Castro Veado et $a^{\beta 7}$ reported a mean postoperative VAS of 1.5 (range 0 - 8 points), the patient with score 8 had an intact RC confirmed by ultrasonography but concomitant irradiating cervical pathology. Djahangiri et $a^{\beta 9}$ reported a $93 \%$ rate of patients who were satisfied or very satisfied. In the study by De Carvalho et al, ${ }^{42} 73$ out of 88 (92.7\%)

Table 2 - Study details

\begin{tabular}{|c|c|c|c|c|}
\hline First author, Year & Population (n) & Procedures (n) & Mean age & Evidence level \\
\hline Bhatia, 2015 & 44 & 49 & 73.00 & IV \\
\hline Charousset, 2010 & 81 & 81 & 70.00 & IV \\
\hline De Carvalho, 2012 & 80 & 88 & 74.20 & IV \\
\hline Djahangiri, 2013 & 41 & 44 & 69.00 & IV \\
\hline Fehringer, 2010 & 39 & 42 & 72.50 & III \\
\hline Flurin, 2013 & 135 & 135 & 74.21 & II \\
\hline Flurin, 2013 & 70 & 70 & 74.60 & II \\
\hline Lam, 2004 & 69 & 69 & 75.00 & IV \\
\hline Miyazaki, 2014 & 163 & 163 & 71.00 & IV \\
\hline Robinson, 2013 & 68 & 69 & 77.00 & IV \\
\hline De Castro Veado, 2015 & 28 & 28 & 70.54 & IV \\
\hline Verma, 2010 & 39 & 39 & 75.30 & IV \\
\hline Worland, 1999 & 69 & 69 & 75.20 & IV \\
\hline Yel, 2001 & 47 & 51 & NA & IV \\
\hline First author, Year & \multicolumn{2}{|c|}{ Validated oucomes } & Outcome results & Outcome \% \\
\hline Bhatia, 2015 & \multicolumn{2}{|c|}{ ASES; Q-DASH; SF12-PCS; SANE } & $90.3 ; 11.3 ; 51.6 ; 85.1$ & $90.30 \%$ \\
\hline Charousset, 2010 & \multicolumn{2}{|c|}{ CSS; SST } & $76.9 ; 32.9$ & $76.90 \%$ \\
\hline De Carvalho, 2012 & \multicolumn{2}{|c|}{ CSS; SST } & $80.1 ; 9.8$ & $80.10 \%$ \\
\hline Djahangiri, 2013 & \multicolumn{2}{|c|}{ CSS } & 78 & $78.00 \%$ \\
\hline Fehringer, 2010 & \multicolumn{2}{|c|}{ CSS; SST } & $85 ; 12$ (healed repairs) & $85.00 \%$ \\
\hline Flurin, 2013 & \multicolumn{2}{|c|}{ CSS; ASES; SST } & $76 ; 90 ; 10$ & $76.00 \%$ \\
\hline Flurin, 2013 & \multicolumn{2}{|c|}{ CSS; ASES; SST } & $80.57 ; 93 ; 10.6$ & $80.57 \%$ \\
\hline Lam, 2004 & \multicolumn{2}{|c|}{ CSS; OSS } & $63 ; 22$ & $63.00 \%$ \\
\hline Miyazaki, 2014 & \multicolumn{2}{|c|}{ UCLA } & 33.6 & $95.00 \%$ \\
\hline Robinson, 2013 & \multicolumn{2}{|c|}{ css } & 58 & $58.00 \%$ \\
\hline De Castro Veado, 2015 & \multicolumn{2}{|c|}{ UCLA; SST; VAS } & $32.39 ; 9.86 ; 1.5$ & $92.54 \%$ \\
\hline Verma, 2010 & \multicolumn{2}{|c|}{ CSS; ASES; SST } & $97.2 \& 88.8$ (\% M\&W); 87.5; 9.8 & $93.00 \%$ \\
\hline Worland, 1999 & \multicolumn{2}{|c|}{ UCLA } & 30,9 & $88.29 \%$ \\
\hline Yel, 2001 & \multicolumn{2}{|c|}{ CSS; ASES } & 82, NA & $82.00 \%$ \\
\hline
\end{tabular}

A: Arthroscopic; Arthro: Arthroscopy; Arthro CT: Arthroscopic Computerized Tomography; ASA: American Society of Anesthesiologists Score; ASES: American Shoulder and Elbow Surgeons Score; BR: Bankart lesion repair; CCS: Case-control study; Clear O \& H: Clear Objective and Hypothesis; CO: Clear Objective; CH: Clear Hypothesis; CP: Cartilage procedures including debridement and bone perforations; CSS: Constant Shoulder Score; CT: Capsulotomy; F/u: Follow up; GC: Goutalier classification; M: Men; MLR: Multivariate Logistic Regression Analysis; MO: Mini-open; MUM: Mumford procedure; NA: Not available; O: Open; OA: Excision of os acromiale; OB: Outerbridge; OSS: Oxford Shoulder Score; Other Cl: Other Classifications; P: Patte classification; PRS: Prospective Randomized Study; Q-DASH: Quick Disabilities of the Arm, Shoulder and Hand Score; ROM: Range of Movement measures; RS: Retrospective study; SAD: Subacromial decompression; SANE: Single Assessment Numeric Evaluation; Sat: Patient subjective satisfaction; SF12-PCS: Short Form-12 Health Survey Physical Component Summary; SLAPR: Superior labral tear anterior to posterior lesion repair; SST: Simple Shoulder Test; TD: Biceps tendon tenodesis; TT: Biceps tendon tenotomy; UCLA: University of California at Los Angeles Shoulder Rating Scale; UltraS: Ultrasound; VAS: Visual Analogue Scale; W: Women 
patients reported satisfaction with their surgery. Yel et al ${ }^{43}$ reported a satisfaction rate of $94.1 \%$ after $\mathrm{RC}$ repair and sub-acromial decompression through an open Rockwood 2-stage acromioplasty-type approach. Bhatia et a/ ${ }^{41}$ reported high satisfaction rates with surgical outcome but 12 $(31 \%)$ patients had a satisfaction rate of 6 or lower, related to strength decrease (population group of recreational athletes).

\section{Rotator cuff integrity control}

Five studies recurred to ultrasound while two used Arthro-CT, for postoperative repair control. Results were homogeneous, with all studies reporting good structural results. Djahangiri et $a^{\beta 9}$ reported healing in $70 \%$ of their cases while $18 \%$ of the open repairs and $19 \%$ of the arthroscopic repairs had not healed. Robinson et $a^{\beta 6}$ reported a re-tear in $20(32 \%)$ out of 62 repairs in a postoperative USS (ultrasonographic) assessment at a median follow up of 14 months (range 1 to 50 ). In the study by Charousset et $a l,{ }^{32}$ the overall rate of re-tears was $42 \%$ and isolated supraspinatus tears showed better tendon healing $(p<0.05)$ than retracted or massive tears $(p<0.05)$. Fehringer ${ }^{44}$ reported $33(78.6 \%)$ out of 42 healed repairs. De Castro Veado et $\mathrm{al}^{37}$ reported re-rupture in 7 (25.9\%) out of 28 patients (the lesion was inferior to $1 \mathrm{~cm}$ in six patients, and $2 \mathrm{~cm}$ in one). Worland et a ${ }^{\beta 8}$ reported CT arthrograms in 17 (25\%) patients: one was watertight, four had a small tear and 12 had large tears, multivariate logistic regression analysis showed that no preoperative variable was independently associated with a favorable outcome;

$\begin{array}{cccc}\text { Study type } & \text { Surgical technique } & \text { Mean F/u (months) } & \text { Associated procedures } \\ \text { RS } & \text { A } & 43.2 & \text { SAD, TT, TD } \\ \text { RS } & \text { A } & 41 & \text { SAD, TT } \\ \text { RS } & \text { MO } & 40.8 & \text { SAD, TD, MUM, OA, Arthro } \\ \text { RS } & \text { O, A } & 57 & \text { SAD, TT, TD } \\ \text { CCS } & \text { MO } & 32.4 & \text { TD } \\ \text { PRS } & \text { A } & 12 & \text { SAD, TT, TD } \\ \text { PRS } & \text { A } & 12 & \text { SAD, TT, TD } \\ \text { RS } & \text { O } & 48 & \text { SAD, MUM } \\ \text { RS } & \text { A } & 50.5 & \text { SAD } \\ \text { RS } & \text { A } & 12 & \text { SAD, TT } \\ \text { RS } & \text { A } & 51.18 & \text { TT, TD, SAD, MUM, SLAPR, BR, CT, CP } \\ \text { RS } & \text { A } & 36.1 & \text { SAD, TT, TD, MUM } \\ \text { RS } & \text { O } & 36 & \text { SAD, MUM } \\ \text { RS } & \text { O } & 115.2 & \text { SAD }\end{array}$

\begin{tabular}{|c|c|c|c|}
\hline Clear O \& H & Statistical analysis & $\mathrm{RCIC}$ & Other $\mathrm{Cl}$ \\
\hline $\mathrm{CO}$ & t-test, Mann-Whinet U, Kruskal-Wallis, Chi-squared, Wilcoxon & NA & $\mathrm{GC}, \mathrm{OB}$ \\
\hline $\mathrm{CO}, \mathrm{CH}$ & Chi-squared, Fisher, MLR & Artro CT & GC \\
\hline $\mathrm{CO}$ & NA & NA & Sat $(\%)$ \\
\hline $\mathrm{CO}$ & Fisher, Mann-Whitney & Ultras & ROM, Sat (\%) \\
\hline $\mathrm{CO}, \mathrm{CH}$ & Fisher, Wilcoxon, $t$-test, MLR & Ultras & NA \\
\hline $\mathrm{CO}, \mathrm{CH}$ & Mann-Whitney U, Fisher & UltraS & GC, SSA, GC, P \\
\hline $\mathrm{CO}, \mathrm{CH}$ & Mann-Whitney U, Fisher & NA & GC, SSA, GC, P \\
\hline $\mathrm{CO}$ & Spearman, Mann-Whitney U, Kruskal-Wallis, MLR & NA & ASA \\
\hline $\mathrm{CO}$ & NA & NA & NA \\
\hline $\mathrm{CO}$ & Chi-squared, Kaplan-Meier & UltraS & NA \\
\hline $\mathrm{CO}$ & Levene, $t$-test & UltraS & NA \\
\hline $\mathrm{CO}$ & $t$-test & NA & GC, ROM \\
\hline $\mathrm{CO}$ & $t$-test, MLR & Artro CT $(25 \%)$ & NA \\
\hline $\mathrm{CO}$ & NA & NA & Sat $(\%)$ \\
\hline
\end{tabular}


Table 3 - Rotator cuff integrity control study

\begin{tabular}{lcc}
\hline First author, Year & RCR healed \% & Outcome \% \\
\hline Charousset, 2010 & 58.0 & 76.90 \\
Djahangiri, 2013 & 70.0 & 78.00 \\
Fehringer, 2010 & 78.6 & 85.00 \\
Flurin, 2013 & 81.5 & 76.00 \\
Robinson, 2013 & 68.0 & 58.00 \\
De Castro Veado, 2015 & 74.1 & 92.54 \\
Mean (\%) & 71.7 & 77.74 \\
\hline
\end{tabular}

RCR: Rotator cuff repair

these results had limited significance given the sample size. The level II study by Flurin et $a^{\beta 3}$ reported the best results but selection criteria was also the strictest: $\mathrm{RC}$ repair healing was achieved in $110(81.5 \%)$ of the reviewed cases, a partial tear was detected in $9(6.5 \%)$ and in $16(12 \%)$, healing failure with full thickness re-tear was demonstrated. Table 3 summarizes the results elegible for analysis.

\section{Reviewed results}

Mean follow up of all studies was 31.14 months (range 12 - 115.2 months). Mean clinical outcome percentage after data workup was $81.34 \%$ (range 58 - 95\%) (Fig. 2). Mean $\mathrm{RC}$ healed percentage of selected studies (Table 3) was 71.7 (SD \pm 8.41).

Studies disposing of the required data, found statistical significance when comparing pre and postoperative outcome scores (Table 4).

Although the lowest score values were reported by Robinson et $a l,{ }^{36}$ the mean pre operative CSS of 23 (SD \pm $14)$ increased to $58(S D \pm 20)$ at one year postoperatively (paired $t$-test, $p<0.001$ ). Djahangiri et $a^{\beta 9}$ reported a mean CSS improvement from 49 points preoperatively (range 5 $74)$ to 78 points (range $23-100$ ) at follow up ( $p<0.05)$; in the same study, the mean CSS was higher in healed repairs (82 points) than non-healed repairs (61 points) $(p<0.05)$.

Charousset $^{32}$ reported a mean CSS improvement from 45.1 points preoperatively (SD \pm 10 ) to 76.9 points (SD \pm

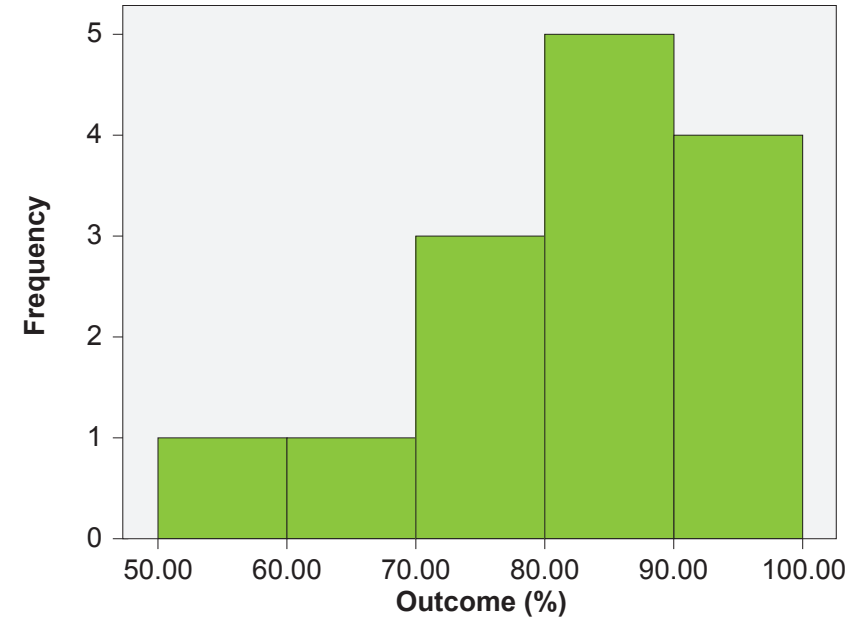

Figure 2 - Histogram of reviewed studies' outcome scores.

Number of reviewed studies by primary outcome score percentages. Mean $=81.34 \%$ $(\mathrm{SD}= \pm 10.85) . \mathrm{n}=14$.

7.8) post operatively and an SST score improvement from 2.4 to 32.9 points $(p<0.01)$. The same study correlated Arthro-CT diagnosed Stage 3 repairs (failed repairs) with lower overall function and strength, when compared to other repair stages (stages $1 \& 2$ tendon healing) $(p<0.01)$. Bhatia et $a^{41}$ reported an ASES score improvement from 56 points to 90.3 points post op and an SF-12 PCS score increase from 43.0 to 51.6 , both with statistical significance $(p<0.001)$. De Castro Veado ${ }^{37}$ reported an UCLA score improvement from 17.46 points to 32.39 points post operative, corresponding to $89.28 \%$ of good and excellent results. Verma et $a /^{19}$ reported ASES score improvement from $45.8(S D \pm 16.6)$ to $87.5(S D \pm 14.4)$ postoperative $(p$ $<0.0001)$. Flurin et $a^{\beta 3}$ found statistical significance $(p<$ 0.001 ) in three outcome scores used to assess functional improvement after RC repair (CCS, ASES and SST); they also found statistical significance when assessing if $R C$ repair and SAD was superior to SAD alone, even though this conclusion is not in the scope of this review. Worland found average improvements of 21.5 points in the UCLA

Table 4 - Statistical value of outcome results

\begin{tabular}{lccc}
\hline First author, Year & Outcome score & Increase (pts) & $\boldsymbol{p}$ value \\
\hline Bhatia, 2015 & ASES & +34.30 & $<0.001$ \\
& SF12-PCS & +8.60 & $<0.001$ \\
Charousset, 2010 & CSS & +31.80 & $<0.01$ \\
Djahangiri, 2013 & CSS & +29.00 & $<0.05$ \\
Flurin, 2013 & CSS & +35.85 & $<0.001$ \\
& ASES & +56.09 & $<0.001$ \\
Robinson, 2013 & SST & +6.33 & $<0.001$ \\
De Castro Veado, 2015 & CSS & +35.00 & $<0.001$ \\
Verma, 2010 & UCLA & +14.93 & $\mathrm{NA}$ \\
Worland, 1999 & ASES & +51.70 & $<0.0001$ \\
\hline
\end{tabular}

Increase (pts): Difference in points between post-operative and pre-operative mean values of each study; $p$ value: Statistical significance of outcome score increase after surgical procedure; ASES: American Shoulder and Elbow Surgeons Score; CSS: Constant Shoulder Score; SF12-PCS: Short Form-12 Health Survey Physical Component Summary; SST: Simple Shoulder Test; UCLA: University of California at Los Angeles Shoulder Rating Scale; NA: Not available 
score after repair $(p<0.001)$.

\section{Methodological evaluation and limitations}

For the purpose of the present review, we identified potential sources of bias in each study.

This systematic review bears its own sources of bias, as it included mostly studies with a lower level of evidence, different treatment methods, and different age cut-off for inclusion. Including these studies, despite evidence level, was paramount, given the scarce literature available regarding this subject.

Power analysis was not reported in any of the papers, which does not give us a lead whether the results were statistically meaningful or not. There were, however, a fair amount of correlations with statistical significance, and the population groups of the different studies were not ignorable. The study with the least cases was from De Castro Veado ${ }^{37}$ and colleagues $(n=28)$, while Miyazaki et $a^{\beta 5}$ had the largest number of reported cases $(n=168)$.

We observed variations between studies, regarding exclusion criteria for patient selection, which provides a source of bias.

Outcome scores used were also diverse. The most frequently used outcome score was CSS (10/14 studies), in the other studies, we used UCLA (3 studies) and ASES (1 study) for data comparison, even though all scores were registered and taken into account.

The execution of different intra-articular and subacromial procedures among the various reviewed studies is also an obvious source of bias, which surely impacts on surgical outcome scores and pain relief. Sub-acromial decompression was, nevertheless, a transversally executed procedure, except in the study by Fehringer. ${ }^{44}$

Some of the selected papers did not have a pre operative outcome score to generate predictive values and others did not perform postoperative imagiologic repair control.

Randomization was reported in both level II studies. Worker's compensation was reported in two patients from the study conducted by Verma et al. ${ }^{1}$

Only seven studies reported the period between beginning of symptoms and surgery, with wide ranges, and this factor may be determinant in influencing outcome scores (Table 5).

Table 5 - Time elapsed from beginning of symptoms until surgery

\begin{tabular}{lcc}
\hline First author, Year & $\begin{array}{c}\text { Symptom to surgery } \\
\text { (months) }\end{array}$ & $\begin{array}{c}\text { Range } \\
\text { (months) }\end{array}$ \\
\hline Bhatia, 2015 & 13.2 & $(0.03-159.6)$ \\
De Carvalho, 2012 & 18.3 & $(1-156)$ \\
Djahangiri, 2013 & 14.0 & $(1-100)$ \\
Lam, 2004 & 18.0 & $(1-58)$ \\
Miyazaki, 2014 & 22.5 & $(0.03-240)$ \\
Robinson, 2013 & 12.0 & NA \\
Worland, 1999 & 10.55 & $(10.55-60)$ \\
\hline NA: Not available & &
\end{tabular}

\section{DISCUSSION}

We understand that RCT prevalence increases with increasing age..$^{2,14,45}$ Furthermore, RCT and healing failures after repair may occur more often in aged patients. ${ }^{46}$ This is confirmed by Robinson et al, ${ }^{36}$ in whose paper the probability of sustaining a re-tear was demonstrated to be higher with increasing size of the RCT $(p=0.042)$. Another remarkable observation in this study, was that age at operation was associated with re-tear-free survival and the risk of a re-tear occurring was a mean of 1.12 times higher than the risk of re-tear in a patient aged one year younger.

Charousset et $a^{\beta 2}$ pinpointed that poor tendon and bone quality, difficulty of tendon reducibility and a high fatty degeneration index were related to the CT findings of a larger number of failed repairs $(p<0.05)$. Therefore, older age results in inferior tear survival rates. It is also true that age has been identified as a major predictor of structural and functional outcome..$^{47,48}$ However, after interpretation of current data, a statistical contrast is obviated when comparing with relevant older studies stating otherwise. A paper from 1995 concludes: "RCT repairs in patients aged older than 65 years have a reported healing rate of only $43 \%$ ". ${ }^{14}$

So, under the light of present knowledge, is it really worthwhile to surgically repair RCT in patients of 65 years and above? And is there improvement of functional outcome, despite worse tendon and bone quality? According to the reviewed studies, the answer is yes to both questions. In the level III case-control study, shoulders with healed repairs had similar SST and CSS scores to those in untreated shoulders with intact rotator cuffs and the healed repair group represented $78.6 \%$ of patients, aged $>65$ years, treated with a mini-open approach. We found a mean of $77.74 \%$ of healed repairs after analyzing postoperative controls of six studies, mainly resorting to USS, a validated imagiologic control method. ${ }^{1}$ Furthermore, in the study by Lam et $a l,{ }^{40}$ functional outcome of those over 80 years old was compared with that of those aged 65 to 79 years and there was no significant statistical difference between the two groups. Another study found excellent five year outcomes after RCT repair in patients older than 65 years when fatty infiltration was not present. Clinical and structural results, in these patients, are comparable to younger patients and withholding rotator cuff repair because of age did not seem justified. ${ }^{39}$ De Castro Veado et $a^{\beta 7}$ found UCLA score improvement in 27 out of 28 patients arthroscopically treated. Flurin et $a^{\beta 4}$ found that the clinical results are not correlated with age or frontal retractions (but only retractions stage 1 and 2 were included in this paper). Healing was, however correlated with the clinical result. It seems that careful selection of patients with clinical and paraclinical data is paramount for a successful outcome.

We have concluded that satisfaction rates with the surgical procedures, in the available studies, were homogeneously high (> $90 \%$ in all).

Although open rotator cuff repairs (RCR) result in more deltoid morbidity than arthroscopic RCR some studies have 
noted comparable findings. The purpose of this systematic review was not to evaluate these two techniques separately, but there appears to be no significant difference in outcome when comparing them.

The minimum follow up of one year, set as a cut-off for this analysis, was based on recent literature. ${ }^{49}$ We believe that this criterion enhances the validity of the extracted data. Lam et $a^{A 0}$ found that female sex, duration of symptoms greater than 34 months before surgery and ASA grade, were preoperative variables significantly associated with poor outcome. Miyazaki et $a^{\beta 5}$ also found that time elapsed between start of symptoms and the surgical procedure showed a statistically significant negative relation with clinical results $(p<0.027)$ (Table 4$)$; a statistical relation between outcome and age progression was not (anecdotally) found.

According to their study results, Flurin et a ${ }^{\beta 4}$ concluded that the optimal profile for repair in older ages is as follows: "A 70+ year-old patient with a mid size tear with minor fatty infiltration (stage 0 and 1 )".

Better results would probably be achieved if all studies had rigorous and homogeneous patient selection criteria, but the fact is, that even though this was not the case, the clinical scores remain favorable, and with statistically significant outcome improvement in all studies with prospectively collected data.

\section{REFERENCES}

1. Smith TO, Back T, Toms AP, Hing CB. Diagnostic accuracy of ultrasound for rotator cuff tears in adults: a systematic review and meta-analysis. Clin Radiol. 2011;66:1036-48.

2. Fehringer EV, Sun J, VanOeveren LS, Keller BK, Matsen FA $3^{\text {rd }}$. Full thickness rotator cuff tear prevalence and correlation with function and co-morbidities in patients sixty-five years and older. J Shoulder Elbow Surg. 2008;17:881-5.

3. Itoi E. Rotator cuff tear: physical examination and conservative treatment. J Orthop Sci. 2013;18:197-204.

4. Milgrom C, Schaffler M, Gilbert S, Van Holsbeeck M. Rotator-cuff changes in asymptiomatic adults. The effect of age, hand dominance and gender. J Bone Joint Surg Br. 1995;77:296-8.

5. Yamaguchi K, Tetro AM, Blam O, Evanoff BA, Teefey SA, Middleton WD. Natural history of asymptomatic rotator cuff tears: A longitudinal analysis of asymptomatic tears detected sonographically. J Shoulder Elbow Surg. 2001;10:199-203.

6. Yamamoto A, Takagishi K, Osawa T, Yanagawa T, Nakajima D, Shitara $\mathrm{H}$, et al. Prevalence and risk factors of a rotator cuff tear in the general population. J Shoulder Elbow Surg. 2010;19:116-20.

7. Brewer BJ. Aging of the rotator cuff. Am J Sports Med. 1979;7:102-10.

8. Burkhart SS, Barth JR, Richards DP, Zlatkin MB, Larsen M. Arthroscopic repair of massive rotator cuff tears with stage 3 and 4 fatty degeneration. Arthroscopy. 2007;23:347-54

9. Tempelhof S, Rupp S, Seil R. Age-related prevalence of rotator cuff tears in asymptomatic shoulders. J Shoulder Elbow Surg. 1999;8:296-9.

10. Mall NA, Kim HM, Keener JD, Steger-May K, Teefey SA, Middleton WD, et. al. Symptomatic progression of asymptomatic rotator cuff tears:a prospective study of clinic and sonographic variables. J Bone Joint Surg Am. 2010;92:2623-33.

11. Harris JD, Pedroza A, Jones GL, MOON (Multicenter Orthopedic Outcomes Network Shoulder Group). Predictors of pain and function in patients with symptomatic, atraumatic full thickness rotator cuff tears: a time zero analysis of a prospective patient cohort enrolled in a structured physical therapy program. Am J Sports Med. 2012;40:359-66.

12. Keener JD, Steger-May K, Stobbs G, Yamaguchi K. Asymptomatic

\section{CONCLUSION}

There is a need to conduct more studies on the current subject, to support the data concluded from this systematic review. To achieve a consistent indication for the surgical repair of rotator cuff tears over 65 years old, a randomized control study comparing two groups with RCT: one surgically repaired versus another with no repair, must be performed.

As the population continues to age, with progressively more active individuals, a standardized treatment for RCT in patients in the age range over 65 years old is paramount.

Based on current literature, rotator cuff repair in patients older than 65 years imparts favorable improvement in clinical outcome scores and overall patient satisfaction.

\section{CONFLICTS OF INTEREST}

The authors declare that there are no conflicts of interest.

\section{FUNDING SOURCES}

This research received no specific grant from any funding agency in the public, commercial, or not-for-profit sectors.

rotator cuff tears: patient demographics and baseline shoulder function. J Shoulder Elbow Surg. 2010;19:1191-8.

13. Yamaguchi K, Sher JS, Andersen WK, Garretson R, Uribe JW, Hechtman K, at. al. Glenoumeral motion in patients with rotator cuff tears: a comparison of asymptomatic and symptomatic shoulders. J Shoulder Elbow Surg. 2000;9:6-11.

14. Beall DP, Williamson EE, Ly JQ, Adkins MC, Emery RL, Jones TP, et al. Association of biceps tendon tears with rotator cuff abnormalities: degree of correlation with tears of the anterior and superior portions of the rotator cuff. Am J Roentgenol. 2003;180:633-9.

15. Murthi AM, Vosburgh CL, Neviaser TJ. The incidence of pathologic changes of the long head of the biceps tendon. J Shoulder Elbow Surg. 2000;9:382-5.

16. Michener LA, McClure PW, Sennett BJ. American Shoulder and Elbow Surgeons Standardized Shoulder Assessment Form, patient self-report section: reliability, validity and responsiveness. J Shoulder Elbow Surg. 2002;11:587-94.

17. Karahan M, Akgun U, Kocaoglu B. Calcific tendonitis. In: Milano G, Grasso A, editors. Shoulder arthroscopy principles and practice. London: Springer-Verlag; 2014. p. 355-63.

18. Rhee YG, Cho NS, Yoo JH. Clinical outcome and repair integrity after rotator cuff repair in patients older than 70 years versus patients younger than 70 years. Arthroscopy. 2014;30:546-54.

19. Verma NN, Bhatia S, Baker CL $3^{\text {rd }}$, Cole BJ, Boniquit N, Nicholson GP, et al. Outcomes of arthroscopic rotator cuff repair in patients aged 70 years or older. Arthroscopy. 2010;26:1273-80.

20. MacDermid JC, Ramos J, Drosdowech D, Faber K, Patterson S. The impact of rotator cuff pathology on isometric and isokinetic strength, function and quality of life. J Shoulder Elbow Surg. 2004;13:593-8.

21. McKee MD, Yoo DJ. The effect of surgery for rotator cuff disease on general health status. Results of a prospective trial. J Bone Joint Surg Am. 2000;82:970-9.

22. Liberati A, Altman DG, Tetzlaff J, Mulrow C, Gøtzsche PC, loannidis JP, et al. The PRISMA statement for reporting systematic reviews and metaanalyses of studies that evaluate healthcare interventions: explanation 
and elaboration. BMJ. 2009;339:b2700.

23. Constant $\mathrm{CR}$, Murley AH. A clinical method of functional assessment of the shoulder. Clin Orthop Relat Res. 1987;214:160-4.

24. Lippitt SB, Harryman DT, Matsen FA $3^{\text {rd }}$. A practical tool for evaluating shoulder function: the simple shoulder test. In: Matsen FA $3^{\text {rd }}, \mathrm{Fu} \mathrm{FH}$, Hawkins RJ, editors. The shoulder: a balance of mobility and stability. Rosemont: American Academy of Orthopaedic Surgeons; 1993. p. 50118.

25. Dawson J, Fitzpatrick R, Carr A. Questionnaire on the perceptions of patients about shoulder surgery. J Bone Joint Surg Br. 1996;78:593-600.

26. Hudak PL, Amadio PC, Bombardier C. Development of an upper extremity outcome measure: the DASH (disabilities of the arm, shoulder and hand). The Upper Extremity Collaborative Group (UECG). Am J Ind Med. 1996;29:602-8.

27. Ware J Jr, Kosinski M, Keller SD. A 12-ptem short-form health survey: construction of scales and preliminary tests of reliability and validity. Med Care. 1996;34:220-33.

28. Williams GN, Gangel TJ, Arciero RA. Comparison of the single assessment numeric evaluation method and two shoulder rating scales. Am J Sports Med. 1999;27:214-21.

29. Amstutz HC, Sew Hoy AL, Clarke IC. UCLA anatomic total shoulder arthroplasty. Clin Orthop Relat Res. 1981;155:7-20.

30. Deranlot J, Flurin PH, Hardy P, Klouche S, French Arthroscopy Society (SFA). A new instrument to measure the activity profile of elderly shoulder pathology patients: the Senior Shoulder Activity score (SSA score). Orthop Traumatol Surg Res. 2013;99:367-70.

31. McCormack HM, Horne DJ, Sheather S. Clinical applications of visual analogue scales: a critical review. Psychol Med. 1988;18:1007-19.

32. Charousset C, Bellaiche L, Kalra K, Petrover D. Arthroscopic repair of full-thickness rotator cuff tears: is there tendon healing in patients aged 65 years or older? Arthroscopy. 2010;26:302-9.

33. Flurin $\mathrm{PH}$, Hardy $\mathrm{P}$, Abadie $\mathrm{P}$, Boileau $\mathrm{P}$, Collin $\mathrm{P}$, Deranlot $\mathrm{J}$, et al. Arthroscopic repair of the rotator cuff: Prospective study of tendon healing after 70 years of age in 145 patients. Orthop Traumatol Surg Res. 2013;99:379-84.

34. Flurin PH, Hardy P, Abadie P, Desmoineaux P, Essig J, Joudet $T$, et al. Rotator cuff tears after 70 years of age: A prospective, randomized, comparative study between decompression and arthroscopic repair in 154 patients. Orthop Traumatol Surg Res. 2013;99: 371-8.

35. Miyazaki AN, da Silva LA, Santos PD, Checchia SL, Cohen C, Giora TS. Evaluation of the results from arthroscopic surgical treatment of rotator cuff injuries in patients aged 65 years and over. Rev Bras Ortop.
2015;50:305-11.

36. Robinson PM, Wilson J, Dalal S, Parker RA, Norburn P, Roy BR. Rotator cuff repair in patients over 70 years of age: early outcomes and risk factors associated with re-tear. Bone Joint J. 2013;95:199-205.

37. De Castro Veado MA, Prata EF, Gomes DC. Rotator cuff injury in patients over the age of 65 years: evaluation of function, integrity and strength. Rev Bras Ortop. 2015;50:318-23.

38. Worland RL, Arredondo J, Angles F, Lopez-Jimenez F. Repair of massive rotator cuff tears in patients older than 70 years. J Shoulder Elbow Surg. 1999;8:26-30.

39. Djahangiri A, Cozzolino A, Zanetti M, Helmy N, Rufibach K, Jost B, et al. Outcome of single-tendon rotator cuff repair in patients aged older than 65 years. J Shoulder Elbow Surg. 2013;22:45-51.

40. Lam F, Mok D. Open repair of massive rotator cuff tears in patients aged sixty-five years or over: Is it worthwhile? J Shoulder Elbow Surg. 2004;13:517-21.

41. Bhatia S, Greenspoon JA, Horan MP, Warth RJ, Millett PJ. Two-year outcomes after arthroscopic rotator cuff repair in recreational athletes older than 70 years. Am J Sports Med. 2015;43:1737-42.

42. De Carvalho BR, Puri A, Calder JA. Open rotator cuff repairs in patients 70 years and older. ANZ J Surg. 2012;82:461-5.

43. Yel M, Shankwiler JA, Noonan JE Jr, Burkhead WZ Jr. Results of decompression and rotator cuff repair in patients 65 years old and older: 6- to 14- year follow up. Am J Orthop. 2001;30:347-52.

44. Fehringer EV, Sun J, Cotton J, Carlson MJ, Burns EM. Healed cuff repairs impart normal shoulder scores in those 65 years of age and older. Clin Orthop Relat Res. 2010;468:1521-5.

45. Sher JS, Uribe JW, Posada A, Murphy BJ, Zlatkin MB. Abnormal findings on magnetic resonance images of asymptomatic shoulders. J Bone Joint Surg Am. 1995;77:10-5.

46. Boileau P, Brassart N, Watkinson DJ, Carles M, Hatzidakis AM, Krishnan SG. Arthroscopic repair of full-thickness tears of the supraspinatus: does the tendon really heal? J Bone Joint Surg Am. 2005;87:1229-40.

47. Harryman DT $2^{\text {nd }}$, Mack LA, Wang KY, Jackins SE, Richardson ML, Matsen FA $3^{\text {rd }}$. Repairs of the rotator cuff. Correlation of functional results with integrity of the cuff. J Bone Joint Surg Am. 1991;73:982-9.

48. Nho SJ, Brown BS, Lyman S, Adler RS, Altchek DW, MacGillivray JD. Prospective analysis of arthroscopic rotator cuff repair: prognostic factors affecting clinical and ultrasound outcome. J Shoulder Elbow Surg. 2009;18:13-20.

49. Abrams, JS. Arthroscopic rotator cuff repair. In: Norris TR, editor Orthopaedic knowledge update. Ilinois: AAOS; 2002. p. 471-8. 